\section{The Doctor's View of War}

Edited by Dr. H. Joules. Pp. 123. (London : George Allen and Unwin, Ltd., 1938.) 3s. 6d. net.

$\mathrm{T}$ HIS admirable little volume has the strongest claims on the attention of all scientific workers. Dr. Joules and his colleagues give a concise but lucid account of the service which the doctor can render in time of war, and the problems he has to face, as well as of the effect of the disregard of the Red Cross emblem in recent years. Much more than this is, however, provided. An ably written chapter deals succinctly with the biological effects of war, and argues that it is doubtful whether a differential mortality between different groups would be great enough to have any evolutionary significance within a short time. It is considered rather that modern war would wreck the present structure of society without any permanent biological damage having been inflicted.

It is, however, for the stimulating and highly suggestive chapters which deal with the professional responsibilities of the doctor towards the State and in the defence of the civilian population that scientific workers should be most grateful. What is written here of the medical profession is equally true of scientific workers of other groups, and the problems which face a professional association in relation to the State and the responsibility that such associations must bear for independent investigation and criticism are admirably presented. If the volume did no more than arouse scientific workers to the responsibility that they must bear in this way for conserving the fragile life of our democratic institutions it would be welcome. It issues, however, a call to wider action on an international scale to eliminate the causes of war, and the responsibility of the doctor or other scientific worker as a private citizen for supporting a foreign policy which insists on such preventive measures is firmly urged. Equally it is urged in conclusion that the medical associations of different countries should take their own collective action to assure ordered scientific progress, nationally and internationally conceived and practised, and that the relations of the profession to the State should be based upon a series of well-defined principles.

\section{These Amazing Electrons}

By Raymond F. Yates. Pp. xiii $+326+46$ plates. (New York: The Macmillan Co., 1937.) 16s. net.

\footnotetext{
7 HIS volume merits serious consideration as an attempt to popularize science, with proper emphasis on its social significance. It is not a mere book of wonders (although they are in it), but an accurate and well-illustrated account of the principles and applications of electronics. The development is not superficial, but it should be possible for anyone to follow it easily who has no more initial knowledge of electricity than is required for the use of ordinary domestic electrical apparatus. Mr. Yates's style is vivid, almost racy, and will probably irritate an academically trained physicist; but it is unlikely to disturb the average lay reader.
}

\section{Advanced Algebra}

By Clement V. Durell and A. Robson. Vols. 2 and 3. Pp. xi+195-510+xxiii-xlvi +4. (London : G. Bell and Sons, Ltd., 1937.) 12s. $6 d$.

7 HIS book, comprising vols. 2 and 3, is intended to complete the school course and to provide a suitable introduction to higher work for those who are proceeding to the universities. Attention has rightly been concentrated upon fundamental principles and methods which are essential to a more advanced study of modern mathematics. Vol. 2 deals with finite series, difference equations, complex algebra, partial fractions, theory of equations, sequences and convergency. In vol. 3 , the student is introduced to those parts of the subject which are of special significance in the modern developments of mathematics - inequalities, determinants, matrices, elementary probability and the theory of numbers.

Throughout, the text has been prepared with much skill, thoroughness and clarity; the methods are up to date and admirably adapted to lay a sound foundation for further study. There is also an abundance of exercises for the student, and these are roughly divided into two groups, the first consisting of straightforward applications of the bookwork, and the second of carefully graded sets of more difficult problems. The book should be very useful, and especially to those who intend to specialize in mathematics.

\section{Engineering Electronics}

By Donald G. Fink. Pp. xiii +358. (New York and London: McGraw-Hill Publishing Co., Ltd., 1938.) $21 s$.

$7 \mathrm{HE}$ author, who is managing editor of the well1 known jourmal Electronics, is in an ideal position for observing the continuous and successful application of electronic devices to industry. Without the subtlety associated with the specialist and research worker, or even a professor, and taking a robust point of view, he has produced a well-balanced text covering ground which has indeed been covered before, but not in a way that a practising engineer can, and ought to, understand. Sufficient theory of electrons in vacuum and gas tubes is included to make the internal and external circuit phenomena of these intelligible. A large number of electronic problems serve to illustrate magnitudes and the possibility of practical use of controls.

L. E. C. H.

\section{The Climates of the Continents}

By W. G. Kendrew. Third edition. Pp. xii +473. (London: Oxford University Press, 1937.) 21s, net

7 HE third edition of Mr. Kendrew's book does not bear any striking outward marks of differing from the earlier editions, but many minor emendations have been made, both in the text and in the tables. The book remains, as before, the most useful and convenient collection of climatic data available in the English language, and not the least of its virtues is that it gives data for the whole world in one set of units. 